\title{
EFFECTS OF LARGE REDUCTIONS AND HEATING TEMPERATURE- TIMES ON GRAIN SIZE CONTROL OF ALLOY 718 ROLLED RINGS
}

\author{
J. Cardenas ${ }^{1}$, H. Guajardo ${ }^{1}$, Chris Harwood ${ }^{1}$, and J.A. Manriquez ${ }^{2}$ \\ ${ }^{1}$ Frisa-Wyman Gordon S.A. de C.V; \\ Av. Valentín G. Rivero 200 Col. Los Treviño; Santa Catarina N.L., 66150 Mexico. \\ ${ }^{2}$ Centro de Innovación en Diseño y Tecnología, Tecnológico de Monterrey, Campus Monterrey; \\ Av. Eugenio Garza Sada 2501 Sur, Monterrey N.L., 64849 Mexico.
}

Keywords: Alloy 718, rolled rings, hot forging, delta solvus, grain size maps, recrystallization.

\begin{abstract}
This paper reports the results of a production-size experiment designed to study the effects of three key process variables on the grain structure of alloy 718 rolled rings. Heating temperatures, furnace holding times as well as part-thickness reduction during the final rolling pass, were varied in a range selected to represent production situations of critical importance for the integrity and mechanical properties of the finished part. Forging temperatures of $1904^{\circ} \mathrm{F}\left(1040^{\circ} \mathrm{C}\right)$ and $1825^{\circ} \mathrm{F}$ $\left(996{ }^{\circ} \mathrm{C}\right)$ were selected to study the effect of $\mathrm{Ni}_{3} \mathrm{Nb}$ delta-phase precipitation around the solvus line. Heating times of 30,90 and 180 minutes were used to study the effects of long residences of the work piece in the furnace prior to final rolling. Reductions of 10, 20 and 30 percent were applied to the parts during the final rolling pass, to investigate appropriate deformations needed to obtain complete recrystallization as well as a homogeneous grain size distribution throughout the part volume (total reductions in each case were, correspondingly, 20, 35 and $60 \%$ ). It was found that the most pronounced effect on grain size came from the interaction of all three variables, with the condition $1825^{\circ} \mathrm{F}\left(996{ }^{\circ} \mathrm{C}\right)-30$ min-30\% producing a grain size average of 8 ASTM. The reduction percent during the final pass and the number of passes during pre-rolling showed a strong effect on the distribution of recrystallized grain sizes along the part volume, which is important for assuring part integrity. The grain recrystallization behavior of alloy 718 forgings was consistent with the grain boundary pinning mechanism known to occur by precipitation of $\mathrm{Ni}_{3} \mathrm{Nb}$ delta phase at forging temperatures.
\end{abstract}

\section{Introduction}

Thermo-mechanical processing of superalloys is a fabrication route widely used to produce rings for aircraft engine applications. It can be a challenging process especially when multi-phase microstructures, complex contouring shapes and tri-dimensional states of stresses, all combine and make it difficult to predict the flow of materials throughout the constantly changing part volume [1]. Computer programs have been developed that simulate deformation behavior of multi-phase alloys under distinct strain conditions. Although these codes have shown that they can be used to reduce development cost for many applications, thermo-mechanical work of multi-phase alloys still remains a complex process where extensive experimentation, both laboratory and full-scale, 
are normally needed to produce a shaped ring with homogeneous properties throughout the entire part volume.

Rings with high part integrity can be produced from superalloy materials by different process routes. A frequently used path is centered on giving the alloy a thermo-mechanical work which produces a micro-structure with recrystallized grains, essential to impart the mechanical resistance that the part needs at high temperatures. For instance, fabrication of fine and ultra-fine grain rings can be consistently produced from alloy 718 by using relatively low forging temperatures and sufficient deformation, precipitating controlled amounts of blocky delta particles $\left(\mathrm{Ni}_{3} \mathrm{Nb}\right)$ for recrystallization of the microstructure [2]. It has been known for many years now that these particles act as pinning sites for grain boundaries [3], slowing down grain growth rates during the periods of time that the part spends at high temperature in the rolling process, giving thus as a final result a part with much improved mechanical properties such as fatigue strength/life [4,5]. Microstructure characteristics such as average grain size, largest grain, and percent of grain recrystallization can be used to effectively evaluate the outcome of a given thermo-mechanical process.

In an interesting study, a Taguchi technique was used to test the statistical significance of initial forging temperature as well as the total gage reduction in controlling recrystallized grain size, recrystallization percentage and hardness in a 718 ring-rolling operation [6]. Within specific test conditions, it was found that forging temperature $\left(1010^{\circ} \mathrm{C}-1120^{\circ} \mathrm{C}\right)$ and reduction percent $(35$ $70 \%$ ), in that order, were the most statistically significant factors in affecting the percent of recrystallization. Recrystallized grain size was mostly affected by temperature and cooling rate. It was also found that some two-way interactions of variables also affected both metallurgical parameters in a significant way. Other process variables such as furnace hold times, strain rates, number of deformation passes and initial grain size were of no statistical significance within the condition limits studied in that experiment.

In another study, the effects of multiple reductions on the grain refinement of a hot worked alloy 718 ingot were analyzed, having as a prime objective to investigate the effects of rolling temperature and the true strain rate [7]. By using multiple stroke axial compression testing of cylindrical specimens it was possible to simulate the microstructure evolution of the material as it suffers primary breakdown. It was found that deformation temperature and time between deformation cycles were the primary production variables for predicting microstructural evolution. Complete recrystallization occurred only at $1150{ }^{\circ} \mathrm{C}\left(2102{ }^{\circ} \mathrm{F}\right)$ and a duplex grain structure was observed as a consequence of multiple reductions steps.

Computer modeling of the forging process is another technique very useful for predicting grain size after multiple deformation steps of an alloy 718. By using isothermal and non-isothermal formulations with experimental correlations into the model, it is shown to be possible to predict grain size and to obtain primary locations for major deformation and dead zones [8,9]. The accuracy of the predictions however is still very dependent on the power of the simulation codes and on the availability of proper metallurgical data for selection of modeling parameters.

This paper presents the results of a full-scale experiment aimed at studying the interacting effects of final forging temperature, furnace hold time (intermediate reheating), and amount of final deformation on the distribution of grain size averages of 718 rolled rings. Long furnace hold times at temperatures above and below the delta phase solvus temperature coupled with significant reduction percents in the final forging step, were studied to take in account for relevant industrial situations of possible occurrence during the thermo-mechanical processing of 718 rolled rings. 


\section{Experimental procedure}

The source material for the study was an 8" diameter VIM-VAR 718 forged billet, with an average grain size of 8.5 ASTM and a base chemical composition as shown in Table I.

Table I. Base chemistry of the alloy 718 used in the present study.

\begin{tabular}{|c|c|c|c|c|c|c|c|c|}
\hline Element & $\mathrm{Ni}$ & $\mathrm{Fe}$ & $\mathrm{Cr}$ & $\mathrm{Mo}$ & $\mathrm{Nb}$ & $\mathrm{Ti}$ & $\mathrm{Al}$ & $\mathrm{C}$ \\
\hline $\mathrm{Wt} \%$ & 52.59 & 18.48 & 18.22 & 3.01 & 5.41 & 1.00 & 0.52 & 0.03 \\
\hline Element & $\mathrm{Si}$ & $\mathrm{Mn}$ & $\mathrm{B}$ & $\mathrm{P}$ & $\mathrm{S}$ & Others & & \\
\hline $\mathrm{Wt} \%$ & 0.10 & 0.06 & 0.004 & 0.004 & 0.0005 & Rem & & \\
\hline
\end{tabular}

$\underline{\text { Ring forging steps }}$

Blanking: the starting billet was firstly heated for two hours at $2012^{\circ} \mathrm{F}\left(1100{ }^{\circ} \mathrm{C}\right)$ and then upset and pierced at the same temperature to convert it into a 15.55 " OD x 5.31" ID x 4.33" $\mathrm{H}$ blank. A 30 minutes intermediate reheating also at $2012^{\circ} \mathrm{F}\left(1100^{\circ} \mathrm{C}\right)$ was applied to complete the upset.

Pre-rolling: the blank was then heated at $2012^{\circ} \mathrm{F}\left(1100^{\circ} \mathrm{C}\right)$ for 30 minutes and pre-rolled to $9.84^{\prime \prime}$ ID in two passes, with an intermediate reheating at the same temperature for 30 minutes.

Final rolling: the pre-formed ring was finally rolled to 14 ", 17.8 " or 31.5 " ID in two passes under specific conditions of interest. Forging temperature (intermediate reheating), furnace hold time (for intermediate reheating) and reduction percent (final pass) values were varied as indicated in Table II. Final geometry was either 20.28" OD x 14.00" ID x 4.00" H, 23.54" OD x 17.80" ID x 4.00 " $\mathrm{H}$, or 35.00 " OD x 31.50 " ID x 4.00" $\mathrm{H}$, and it was determined by the requirement to impart a specific amount of deformation, correspondingly $10,20,30 \%$, to the alloy during the final forging step.

Table II. Experimental conditions of a $2^{3}$ experimental design for the final forging step.

\begin{tabular}{|c|c|c|}
\hline & Low & High \\
\hline Rolling temperature $\left({ }^{\circ} \mathrm{F}\right)$ & 1825 & 1904 \\
\hline Furnace time (min) $*$ & 30 & 90,180 \\
\hline Reduction at final step $(\%)$ & 10 & 30 \\
\hline
\end{tabular}

* 90 minutes is a high level for forging at $1904{ }^{\circ} \mathrm{F}$, while 180 minutes is high level for forging at $1825^{\circ} \mathrm{F}$. This strategy does not allow for obtaining DoE statistical measurements the classical way, but it was applied so in lieu of interest on practical scenarios.

Billet upsetting was conducted on a 3000 Ton. press and rolling was carried out using a 400 Ton. radial/axial ringmill machine. Every piece-job was loaded into- and called from a web-based master information system to standardize non-objective process variables.

Furnace heating was performed in a gas fired box type furnace with a $+/-14^{\circ} \mathrm{C}$ capability. Transfer times were kept to a minimum by using a furnace located next to the forging equipment. Percent reductions were calculated taking cross-sectional areas of both blank and final rolled rings as base references.

Grain size and macro-structure were characterized as per E50TF133 and ASTM E112 specifications and average sizes reported as ASTM numbers followed by the as-large-as number. Grain sizes were measured both along longitudinal and transversal directions from inside the finished part. 


\section{Results and discussion}

Blanking

Figure 1 is an optical micrograph showing the grain microstructure of the starting 718 billet. The microstructure at this stage showed a homogeneous average ASTM grain size of 8.5 (as large as: ala 7) except at the cylinder axis where grains as large as 4 were observed. These averages held true when measured along both transversal and longitudinal directions. The 5:1 reduction of the billet increased the grain size to averages of 5 (ala 4). Heating this microstructure an additional 30 minutes at $2012^{\circ} \mathrm{F}\left(1100^{\circ} \mathrm{C}\right)$ further increased averages into the 2 (ala 1) and 2.5 (ala1) range.

Pre-rolling

Opening the ID to $10^{\prime \prime}$ at $2012^{\circ} \mathrm{F}\left(1100^{\circ} \mathrm{C}\right)$ yielded a re-crystallized grain structure. When the forging was done in one step, a complex distribution of grain sizes resulted with most of the piece showing 6.5 (ala 4), see Figure 2. A large region of grains with average size around 6.5 ASTM is observed in the center of the piece, while varied grain sizes are observed around; dispersed grains as large as 3 were found. Figure 3 shows a general view and a grain size map for a ring pre-rolled in six steps with intermediate heatings at $2012{ }^{\circ} \mathrm{F}\left(1100{ }^{\circ} \mathrm{C}\right)$ for 30 minutes between steps. Increasing the passes to six had the effect of producing a very homogeneous grain size distribution with an average around 4.3. It was found that two passes with an intermediate heating were enough to produce a homogeneous grain size distribution, and this was applied to the parts that were processed through final rolling.

\section{Final rolling}

Final rolling of the ring to specified diameters and according to the conditions in Table II yielded grain size averages which are summarized in Figure 4. As observed, all three studied factors had a significant effect on grain size within the studied ranges.

A forging temperature of $1825^{\circ} \mathrm{F}\left(996^{\circ} \mathrm{C}\right.$; below delta phase-solvus) produced a grain finer than 4.5 ASTM, even when 180 minutes were given to the part inside the furnace as an intermediate step before final rolling with small deformations. A deformation of $30 \%$ produced fine grains at the lower temperature but the grain did grow significantly when heated for 90 minutes at $1904{ }^{\circ} \mathrm{F}$ $\left(1040{ }^{\circ} \mathrm{C}\right)$ suggesting that the effect of temperature overrides that of deformation. This result is in agreement with results from other experiments previously reported [6]. The furnace time almost did not affect average grain size when the part was final forged at $1825^{\circ} \mathrm{F}\left(996^{\circ} \mathrm{C}\right)$.

The highest effects on grain size were produced by three-way interactions, with the condition $1825^{\circ} \mathrm{F}\left(996^{\circ} \mathrm{C}\right)-30 \mathrm{~min}-30 \%$ producing a grain size average of 8 ASTM, see Figure 5, and the condition $1904{ }^{\circ} \mathrm{F}\left(1040{ }^{\circ} \mathrm{C}\right)-90$ min-10\% producing a corresponding average grain size of 3.5 ASTM, see Figure 6.

The results presented here show that the forging temperature effect on grain microstructure may override those of reduction percent and heating time, therefore emphasizing the care that should be taking when selecting the set of forging conditions for small 718 alloy rings. They also show that furnace holding times over 30 minutes may increase the average grain size in a significant way when forging at temperatures of $1904^{\circ} \mathrm{F}\left(1040^{\circ} \mathrm{C}\right)$ or above, which may deteriorate the resulting integrity of mechanical properties of the part. 


\section{Conclusions}

- All three studied factors, forging temperature, furnace holding time, and final reduction percent were significant in affecting the grain size averages. The interaction of all three factors was even more important, producing very homogeneous grain size distributions with averages above 8 ASTM when temperature was $1825^{\circ} \mathrm{F}\left(996^{\circ} \mathrm{C}\right)$, reduction was 30 $\%$ and furnace holding time was only 30 minutes, and averages around 3.5 ASTM when temperature was $1904{ }^{\circ} \mathrm{F}\left(1040{ }^{\circ} \mathrm{C}\right)$, reduction was only $19 \%$ in final rolling and an extended holding time of 180 minutes was given to the alloy prior to final rolling.

- Furnace temperature was clearly the most significant factor within the range applied in this study. At $1904{ }^{\circ} \mathrm{F}\left(1040{ }^{\circ} \mathrm{C}\right)$ the GS averages ranged in 3.5 to 5.5 ASTM and were almost independent of reduction percents. At $1825^{\circ} \mathrm{F}\left(996{ }^{\circ} \mathrm{C}\right)$ the $\mathrm{GS}$ averages ranged in 6.0 to 8.3 ASTM, becoming finer with both furnace holding time and reduction percent.

- Pre-rolling conditions were important to obtain microstructures with homogeneous grain size distributions. At least two passes during pre-rolling were necessary to complete recrystallization throughout the part volume.

- Long furnace holding times can become critical for obtaining fine grain microstructures if temperature goes above $1825^{\circ} \mathrm{F}$. Near $1904^{\circ} \mathrm{F}\left(1040^{\circ} \mathrm{C}\right)$ it will be necessary to apply greater reductions and short heating times to obtain GS averages of 6 ASTM or finer. This is important in the forging process when small and relatively slim parts need to be fabricated, as it becomes a challenge to the operators to apply enough deformation for recrystallization in one pass without distorting it.

\section{Acknowledgments}

The authors acknowledge the assistance and technical support of Wyman-Gordon Co. (Houston) and GE Aircraft Engines Center (Evandale).

\section{References}

1. N. A. Wilkinson, "Forging of 718 - The importance of T.M.P”, Superalloy 718 -Metallurgy and Applications, ed. E.A. Loria, (TMS 1989), 119-133.

2. A.W. Dix, J.M. Hyzac, and R.P. Singh, "Application of Ultra Fine Grain Alloy 718”, Superalloys 1992, ed. S.D. Antolovich et.al. (TMS 1992), 23-32.

3. R.S. Cremisio, H.M.Butler, and J.F. Radavich, "The Effect of Thermomechanical History on the Stability of Alloy 718", Journal of Metals (Nov 1969), 55-61.

4. Brown, Boettner, and Ruckle, "Minigrain Processing of Nickel Base Alloys", $2^{\text {nd }}$ International Symposium on Superalloys, (Seven Springs PA. Sept. 1972), Superalloys - Processing, L1-L12.

5. D.D. Krueger, S.D. Antolovich, and R.H. Van Stone, "Effects of Grain Size and Precipitate Size on the Fatigue Crack Growth Behavior of Alloy 718 at $427^{\circ} \mathrm{C}$ ", Metallurgical Transactions $A, 18$ A, (August 1987), 1431-1449.

6. D.R. Nielsen, et al., "Grain Size Control in Ring-Rolled Alloy 718”, Superalloys 718, 625, 706 and Various Derivatives, ed. E.A. Loria (TMS, 1994), 373-392.

7. M.C. Mataya and D.K. Matlock, "Effects of Multiple Reductions on Grain Refinement during Hot Working of Alloy 718”, Superalloy 718 - Metallurgy and Applications, ed. E.A. Loria (TMS 1989) 155-178.

8. $\quad$ P.E. Mosser et al., "Metallurgical Aspects of Forge Modeling in Alloy 718", Superalloy 718 Metallurgy and Applications, ed. E.A. Loria (TMS 1989) 179-188.

9. Christina Boyko, Hani Henein, and f. Robert Dax, "Modeling of the Open-Die and Radial forging Processes for Alloy 718”, Superalloys 718, 625, and Various Derivatives, ed. E.A. Loria (TMS 1991) 107-124. 


\section{Figures}

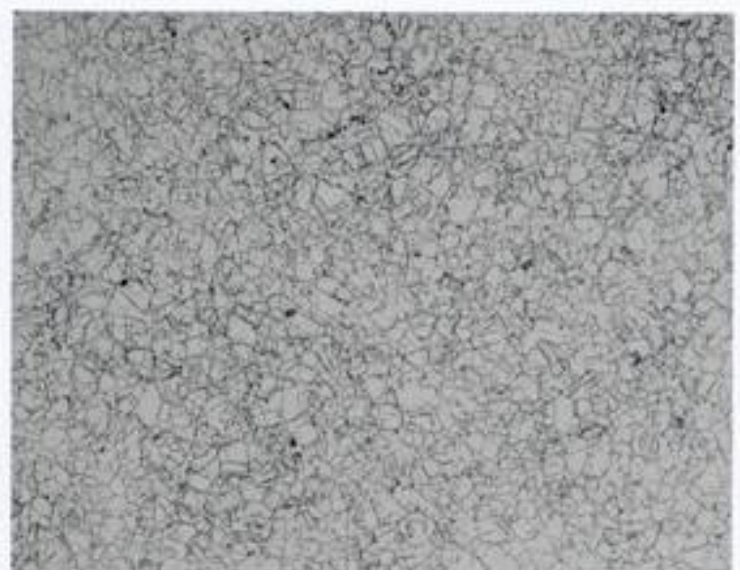

60-B 100X Transversal

Figure 1. Grain microstructure of starting 718 billet used for ring forging experiments.

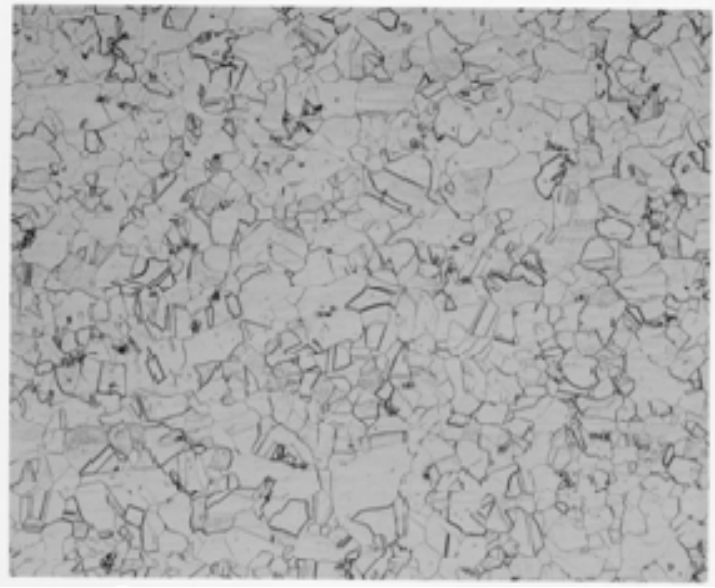

65 Tranevereal

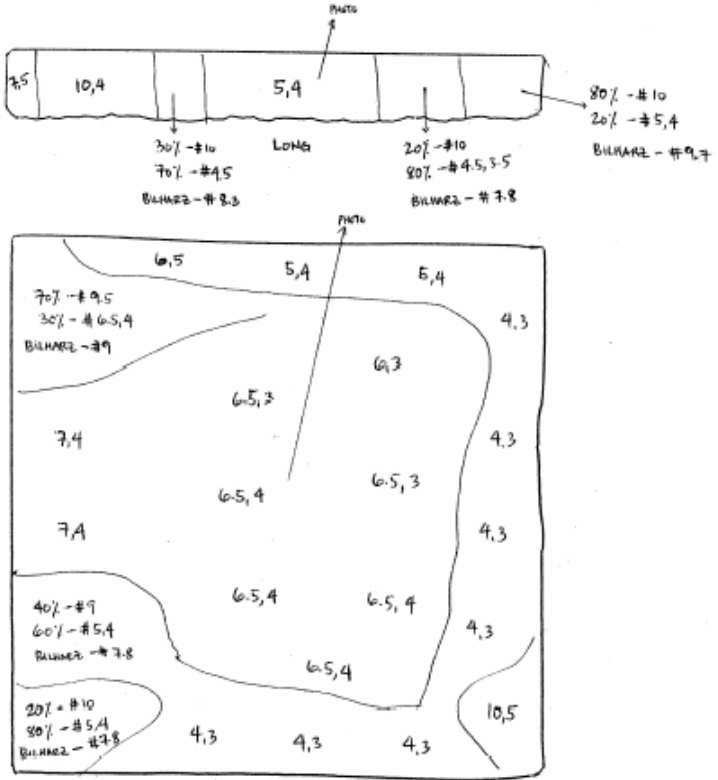

AxIAL

Figure 2. The grain microstructure of a ring pre-rolled in one pass. The right picture shows the inhomogeneous grain distribution across the part volume. 

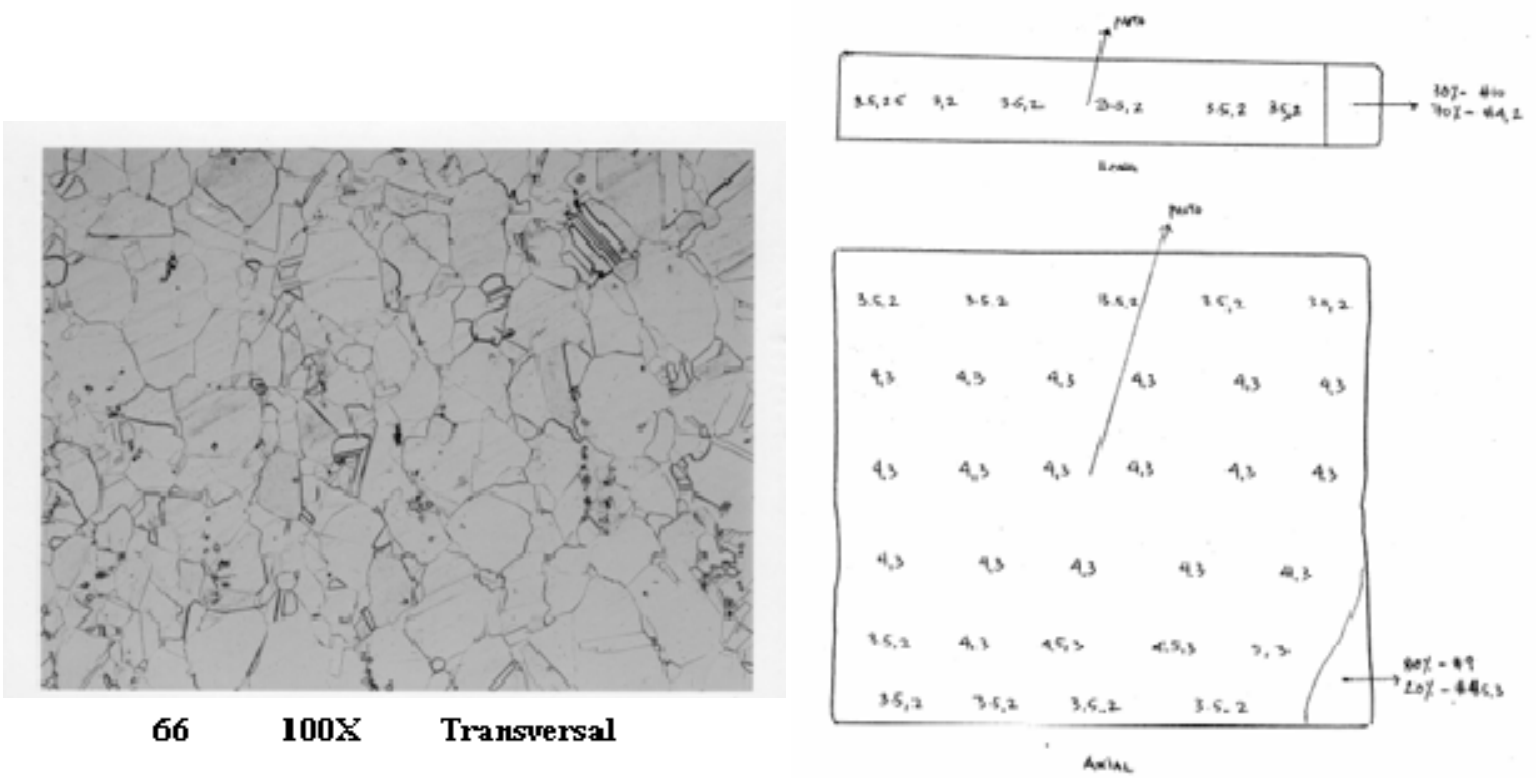

Figure 3. The grain microstructure of a ring pre-rolled in six passes with intermediate heatings of 30 minutes at $2012^{\circ} \mathrm{F}\left(1100^{\circ} \mathrm{C}\right)$ between passes. The right picture shows the homogeneous grain distribution but large size average across the part volume.

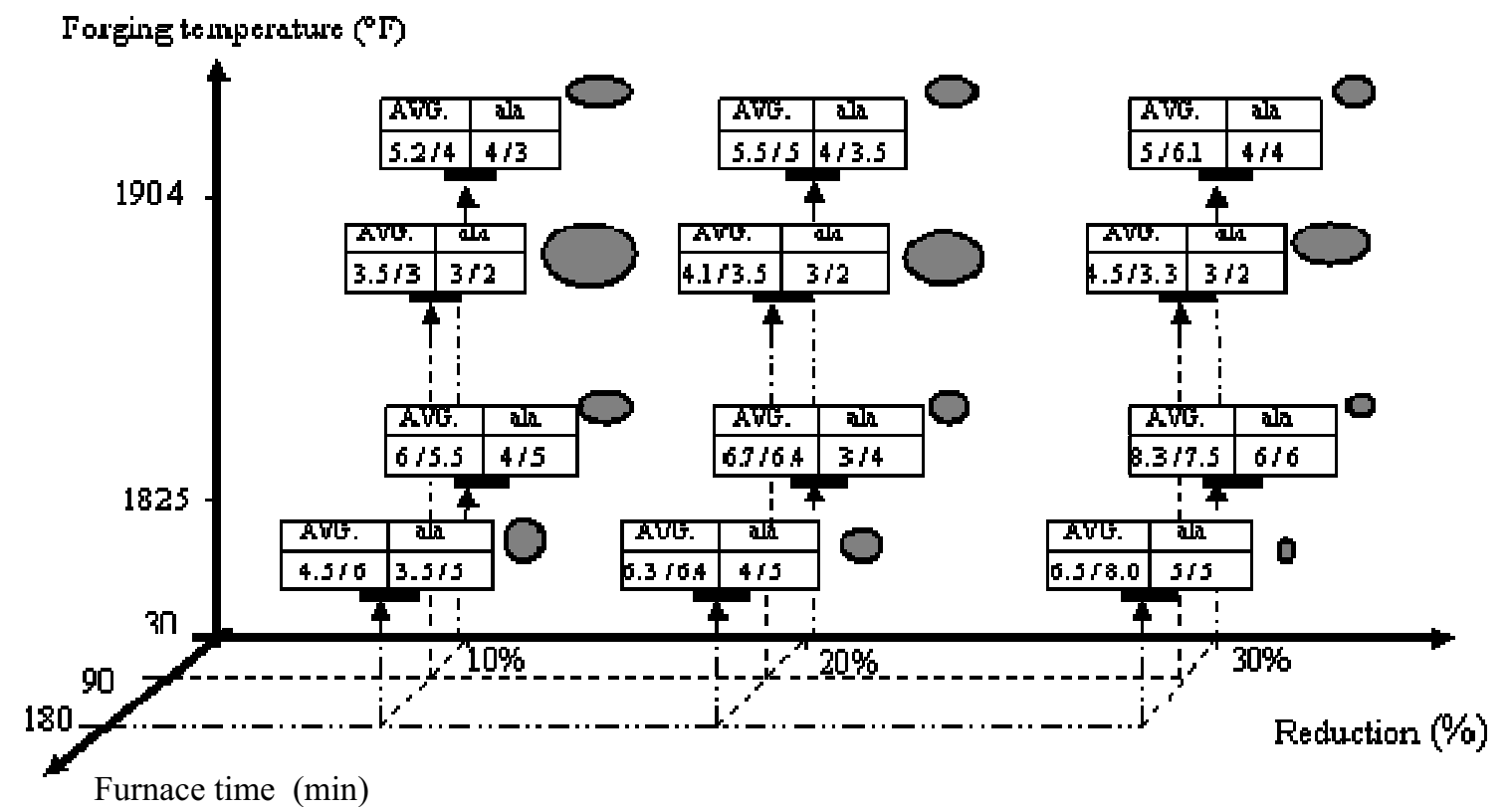

Figure 4. Grain sizes obtained from the experiment under different process conditions. The first average value represents the longitudinal measurement and the second value is the transversal measurement. The term "ala" represents the size for the largest grain observed. 


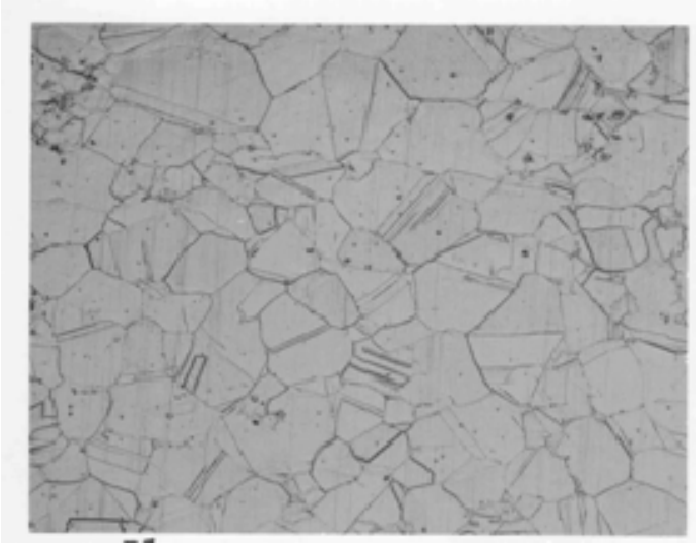

$73100 \mathrm{X}$ Longitudimal

Figure 5. Optical micrograph showing the grain structure of a ring rolled at $1825^{\circ} \mathrm{F}\left(996^{\circ} \mathrm{C}\right)$ in two passes with intermediate heating of 30 minutes at $2012{ }^{\circ} \mathrm{F}\left(1100{ }^{\circ} \mathrm{C}\right)$ between passes and a $10 \%$ reduction during final pass (30\% total reduction).
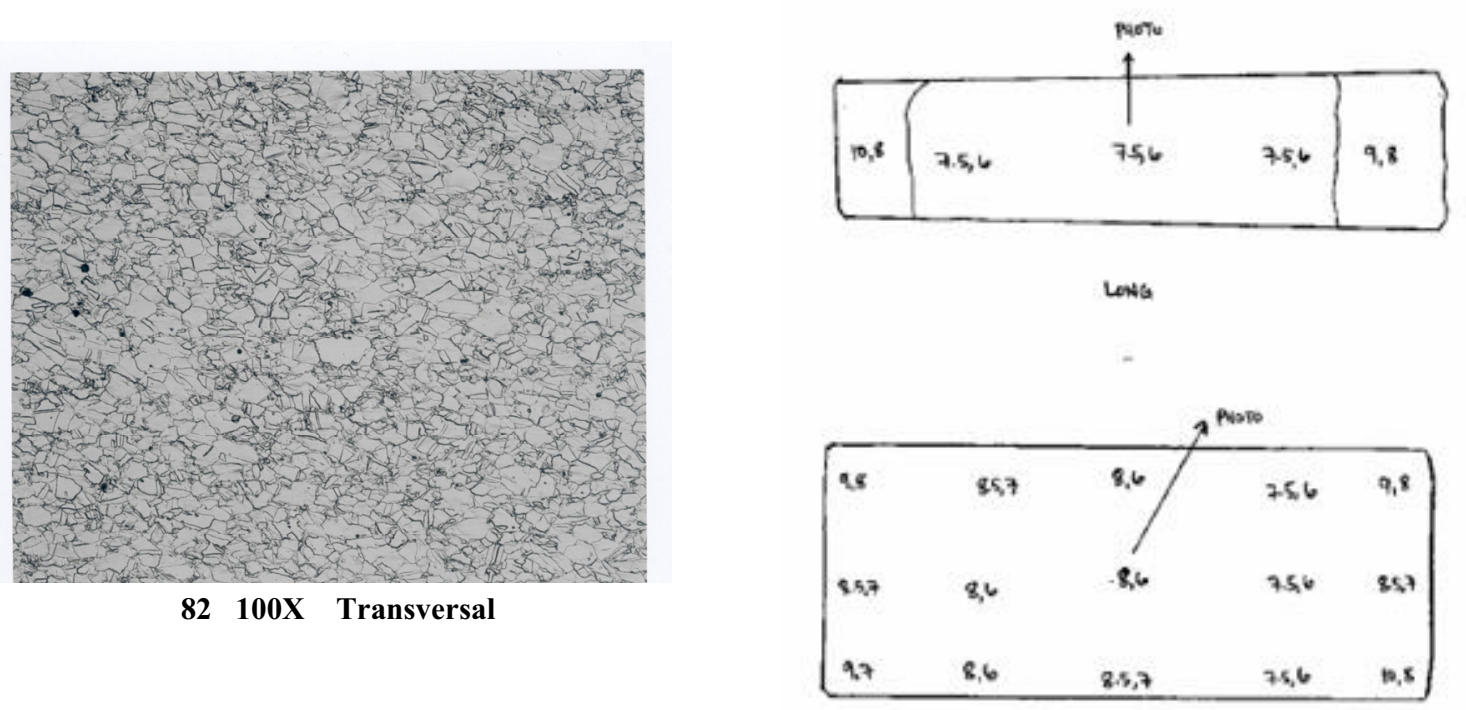

Figure 6. Optical micrograph showing the grain structure of a ring rolled at $1904{ }^{\circ} \mathrm{F}\left(1040{ }^{\circ} \mathrm{C}\right)$ in two passes with intermediate heating of 30 minutes at $2012^{\circ} \mathrm{F}\left(1100^{\circ} \mathrm{C}\right)$ between passes and a $30 \%$ reduction during final pass $(60 \%$ total reduction $)$. 